\title{
DISCUSSION
}

\section{An alternative mechanism of pile failure in liquefiable deposits during earthquakes}

\author{
S. BHATTACHARYA, S. P. G. MADABHUSHi and M. D. BOLTON (2004). Géotechnique 54, No. 3, \\ $203-213$
}

N. Yoshida, Oyo Corporation

I. Towhata, Tokyo University

S. Yasuda, Tokyo Denki University

M. Kanatani, Central Research Institute of Electric Power Industry (CRIEPI)

This paper includes an interesting viewpoint on the damage to piles in liquefiable deposits. However, the writers are afraid that the authors misunderstood actual features of damage to piles.

The authors assume that the pile tip does not move horizontally, and the pile top moves freely in the horizontal direction in Fig. 2. In reality, however, the pile top cannot move freely in the horizontal direction. It is fixed to the foundation and superstructure, and a non-liquefied layer exists at the ground surface, whose thickness is at least a few metres in many cases. Therefore the pile tip must carry them when it moves horizontally, but it is unrealistic to consider that the buckled pile pushes these huge masses to cause horizontal displacement of the ground of several tens of centimetres to several metres. If a non-liquefied layer provides resistance, the buckling mode shown in Fig. 2 does not occur; there must be a fixed support at one end and a pin support at the other end, or fixed at both ends. Then the effective length is one-third or less of that shown in Fig. 2. In addition, damage to the pile must occur not only at the ends but also at the mid depth of the liquefied layer. This is a very important feature to help recognise the cause of pile damage.

Much research has been done to find locations of cracks in piles by, for example, excavating piles, pulling piles out from the subsoil, borehole camera, and integrity tests (e.g. Yoshida \& Hamada, 1990; Hamada \& O’Rourke, 1992; Kinki Branch of Architectural Institute of Japan, 1996;
Hanshin Expressway Public Corporation, 1997; BTL Committee, 2000; Editorial Committee for the Report on the Hanshin-Awaji Earthquake Disaster (1998)). Figs 17-19 show several examples obtained from these investigations, in which soil profiles and damage patterns of piles are shown. All past investigations, including the cases in Figs 17 to 19, showed that cracks were observed near the bottom and top boundaries between liquefied and non-liquefied layers, or at the pile top. The former type of damage occurred in the ground where liquefaction or liquefaction-induced flow was observed, and the latter occurred when the inertia force of the superstructure acted predominantly. However, no significant damage was observed at the mid depth of the liquefied layer. This research has indicated that damage to piles was caused by liquefaction-induced flow for the former type of damage. Actually, all the pile damage in Table 1 except Sl. no. 4 was reported to be caused by liquefaction-induced flow. No damage to the pile was reported for the piles of Kobe Shimin hospital, as far as the writers know.

Horizontal displacement was measured in some cases (e.g. Yoshida \& Hamada, 1990; Hamada \& O'Rourke, 1992). The displacement of the piles was found to agree with the horizontal displacement. These facts strongly indicate that damage to piles is caused by liquefaction-induced flow.

There are a few cases where a kink in the piles was found at the mid depth (in the liquefied layer), as shown in Fig. 11(d). This type of damage was observed only when the structure was very close to a quay wall which moved towards the sea significantly. Damage to piles of this type was reported to be caused by liquefaction-induced flow (Tokimatsu et al., 1997; Shimura et al., 2000); differences of horizontal displacement of ground between the seaward
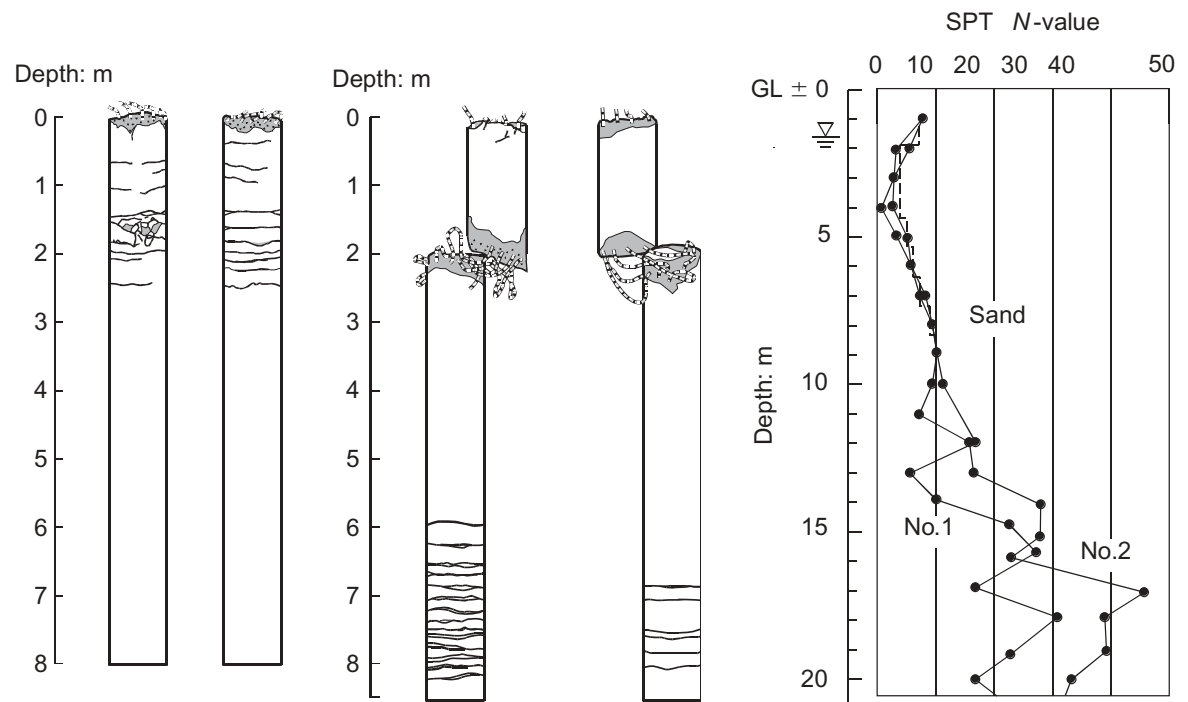

Fig. 17. Building in Niigata City (Yoshida \& Hamada, 1990) 


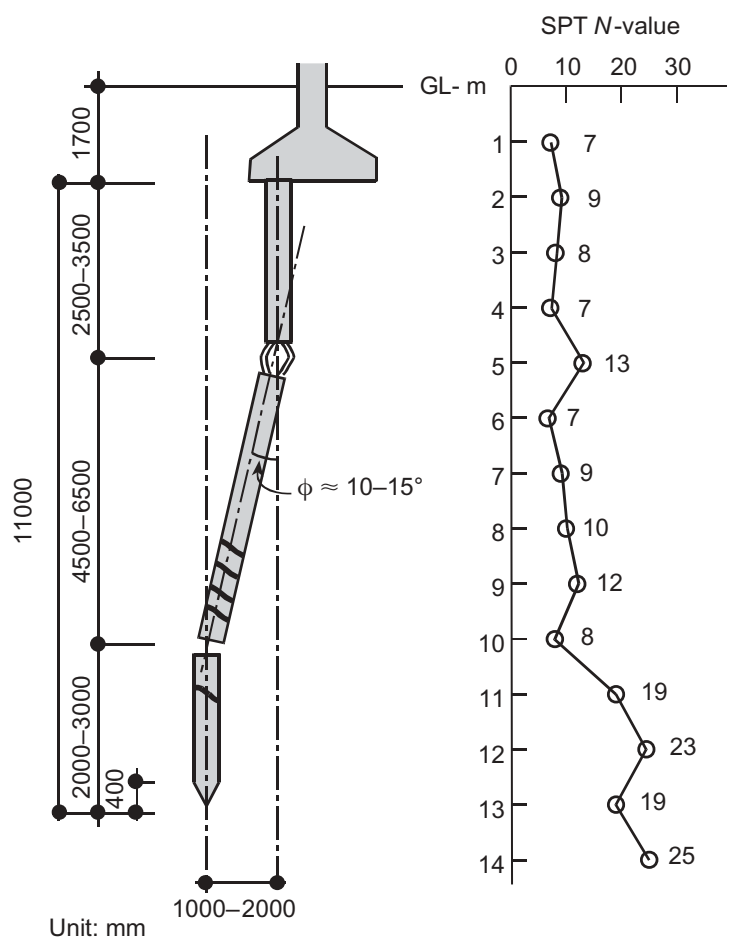

Fig. 18. Building in Niigata City (Kawamura et al., 1985)

pile and the landward pile are responsible for causing this kind of damage.

As shown above, damage to piles was caused by horizontal displacement of the surface ground (unliquefied layer) relative to the foundation ground, which is caused by soil liquefaction or liquefaction-induced flow, but it was not caused by the buckling of the pile.

\section{Authors' reply}

The authors thank the discussers for their further information. However, this supports the authors' theory rather than refuting it, as the discussers suppose.
The discussers propose that there is a non-liquefied layer overlying liquefiable sand, and within which the pile cap is constructed. In Table 1 of the paper we included data from 14 field studies of piled foundations in liquefiable sand that had suffered earthquakes. Some survived and others failed, and our Figs 3 and 4 showed that slenderness and buckling differentiated between the two, irrespective of whether the ground surface sloped or not. All the cases 7 to 14 inclusive, in which piles failed, were on sites in which the groundwater table was no lower than $2.0 \mathrm{~m}$ below the ground surface. Significant failures such as those of the Showa Bridge (case 9) and the Yachiyo Bridge (case 10) were of foundations located below water level, and where the neighbouring soils were also loose, submerged sands. There was no nonliquefied crust in the centrifuge model tests that we reported. It is therefore not clear to which cases of a non-liquefied layer the discussers were drawing attention.

The authors do, however, accept that in some cases there will be a substantial crust of stabilised soil or unsaturated sand, which may modify the top boundary conditions when checking against buckling: Fig. 20 shows four possible cases. Where piles of diameter $D$ pass through a depth more than $5 D$ of stiff soil, it would not be unreasonable to take that portion of the pile as being restrained against rotation, so that the crust in case 3 will have the same effect as the base slab in case 2 . If the portion passing through $5 D$ of stiff soil is at the pile toe, and there is no lower layer of liquefied material, the toe could also be regarded as being fixed in location, as presumed in all four cases in Fig. 20. If, however, that stiff soil layer is present as a non-liquefied crust at the top of the pile, it remains to be asked whether the crust is free to translate or not. If, as the discussers obviously believe, crusts inevitably spread laterally, it must follow that no restraint can be offered against sway of the pile crest, as indicated in case 3 . Only where the crust was somehow prevented from sliding, as in the rather unlikely scenario of case 4, could the pile be best regarded as completely fixed at both ends, with an effective length of half the liquefiable soil thickness. Only in case 4 might it be predicted that damage would be detected at the middle of the pile. The discussers' evidence that no such damage

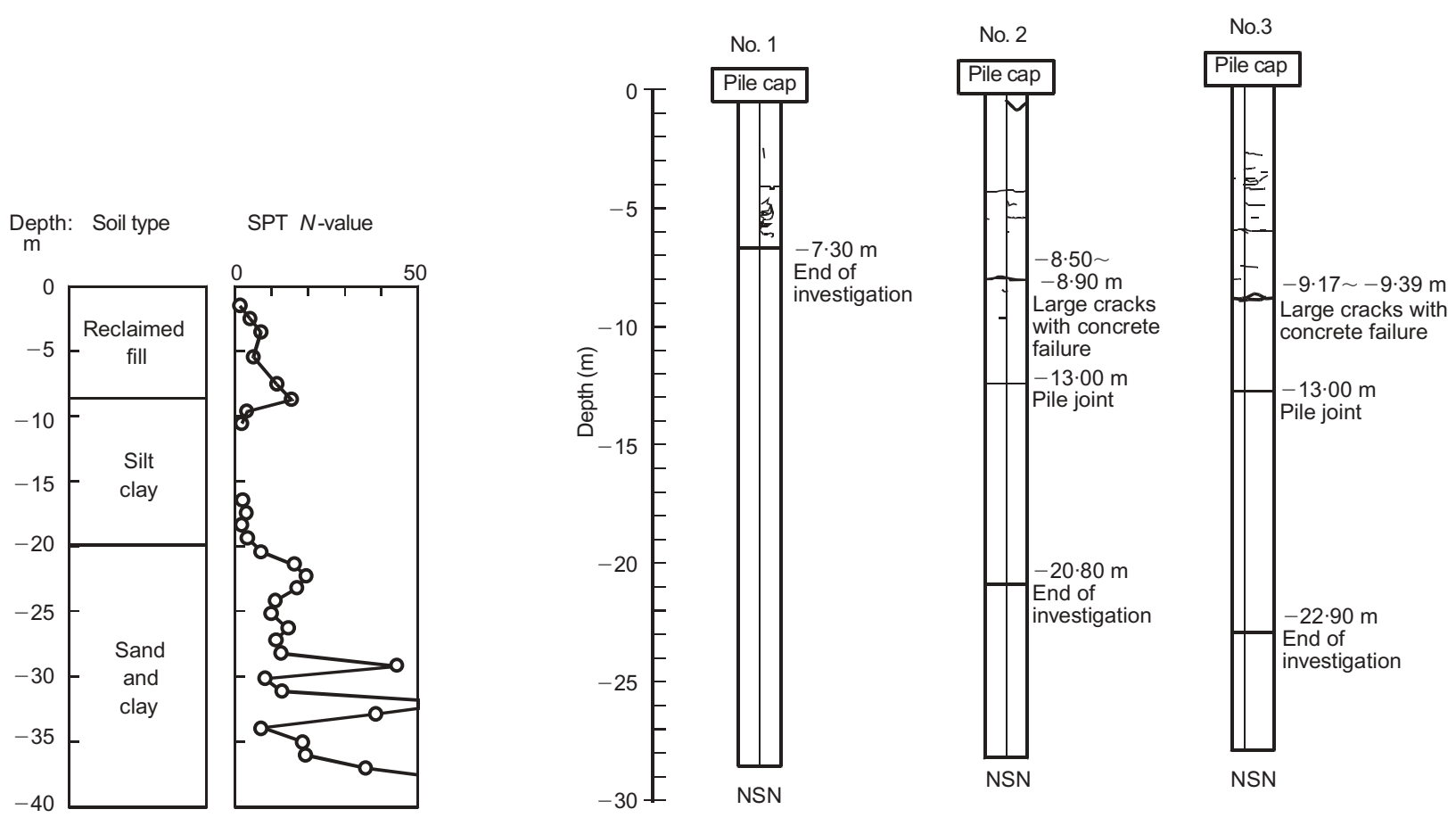

Fig. 19. Building in Kobe city (Fujii et al., 1998) 


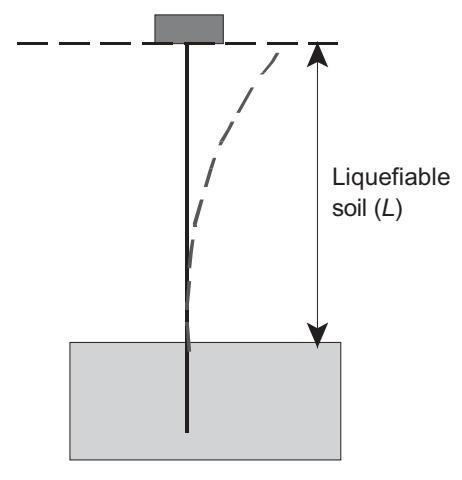

Case 1

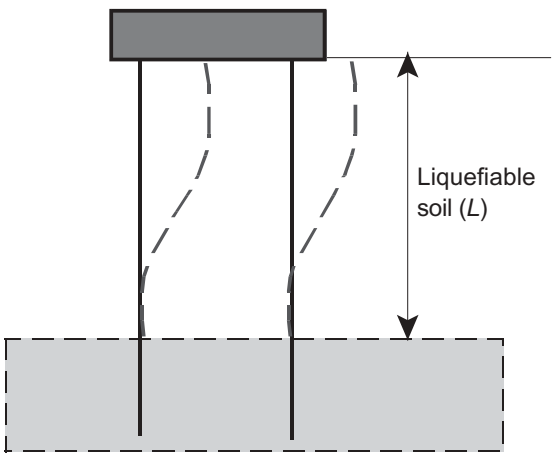

Case 2

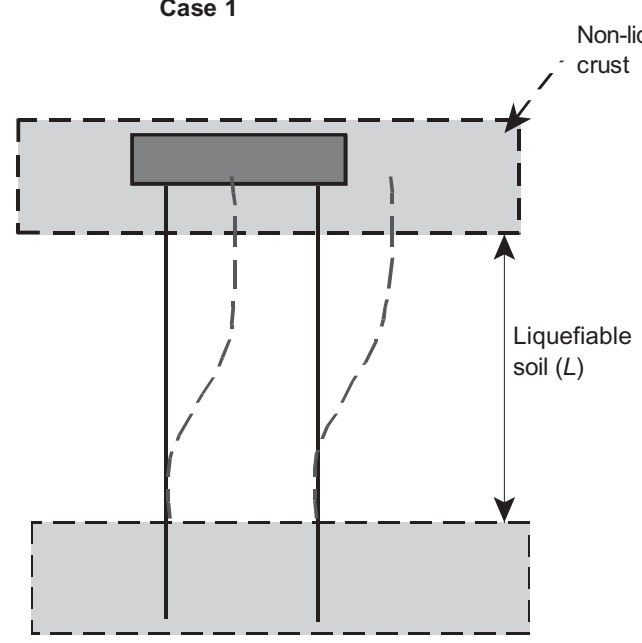

Case 3

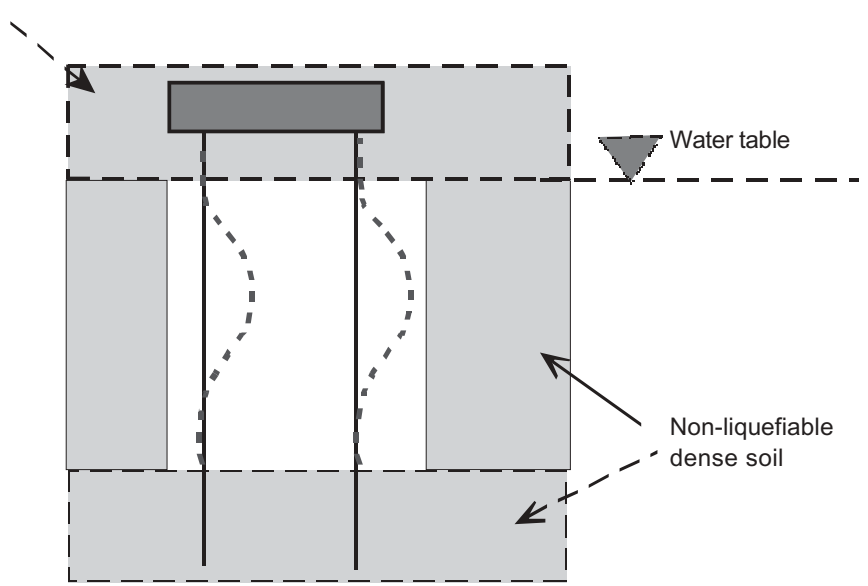

Case 4

Fig. 20. Cases of effective length of piles

occurs simply shows how unlikely it is that a crust of nonliquefied soil can prevent a pile cap from displacing laterally.

The discussers also volunteer the observation that the displacement of pile caps has been found to agree with the horizontal ground displacements. This is exactly the scenario sketched in Fig. 20, case 3. The discussers' belief that this strongly indicates that the damage to the pile is caused by liquefaction-induced flow is, therefore, shown to be incorrect. If a pile manages to retain any lateral stiffness while the crust slides past, there would be evidence of a passive soil zone upstream of the pile cap and a gap between the pile and the crust downstream, in addition to pile damage. Lack of this evidence supports the notion that the pile must have lost its resistance to lateral forces, through the onset of buckling, prior to lateral spreading.

\section{Ghosh, IMD-EREC, India; formerly University of Tsukuba, Japan}

The authors have addressed a very interesting issue of pile failures in liquefiable soil deposits. Based on the 14 case records (mostly from Japan) the authors have shown that $L_{\text {eff }} / r_{\min }=50$ is a borderline between poor and good performance of a piled foundation. However, centrifuge tests performed by the authors (Table 5, Test ID-SB-03, and Figs 4 and 10) have revealed that for $L_{\text {eff }} / r_{\min } \leqslant 120$, model piles did not collapse. Considering pile failure by the authors' proposed buckling instability mechanism, the discusser would like to make the following points:

(a) The authors have evaluated the critical load for a single pile only. What is the effect of the pile group? (b) The $\beta$ factor shown in Table 1 seems to be influenced not only by the type of fixity at the pile head but also by the depth of the liquefying zone. Extra pile length embedded into non-liquefying hard strata may also be an important consideration to take into account for the fixity. In cases $7,8,10,13$ and 14 more than $75 \%$ of the pile length passed through the liquefied region.

(c) The authors have pointed out that, owing to liquefaction, the pile loses lateral support, yet it has to carry axial load under diminishing confining pressure around the pile. Accordingly the authors advocate that the loss of lateral support leads to buckling instability of the pile. In this regard the discusser would like to mention that, under constant volume, the bulk density of liquefied soil remains more or less the same. However, owing to the frequent occurrence of soil subsidence during earthquakes, the density of a loose soil tends to increase. Although the skin friction momentarily reduces to zero, the confining pressure on the pile does not.

(d) The load capacities of the most of the piled foundations built after 1980s in the Kobe port area, for example, were based on the resistances offered by the nonliquefied soil strata. This means that piles were safe enough to transfer the designed axial load to the hard strata even during an earthquake. Lateral support and positive skin friction in the liquefying zone are neglected in seismic design of piles. The confining pressure of the soil in the liquefying zone still exists, even though its positive effect (e.g. not allowing the pile to be laterally unsupported) is often neglected in the design of piles. Therefore, under apparently 
unchanged soil density and confining pressure, and for piles safe enough to transfer axial load to the nonliquefied strata, it is not clear to the discusser how buckling may occur in the liquefied zone.

(e) In order to account for the uncertainties in pile design the actual overall factor of safety provided is quite high. If buckling criteria based on geometric stiffness are incorporated into the design as in Fig. 21 (Bhattacharya \& Tokimatsu, 2004), then a compromise between economic feasibility and design of pilesupported structures must be sought.

Based on extensive investigations of many failed structures in Japan and the USA, it is now an established fact that large deformation of the ground seems to support the observation that most of the piled foundations collapsed as a result of 'lateral spreading'. Damage to piles at shallow and deep elevations, dislocation of pile-cap connections, rotations of pile heads and pile caps with corresponding effects on the superstructure have been observed (Abdoun and Dobry, 2002). A number of centrifuge and shaking table tests have revealed that piles sustain large damage at the interface of

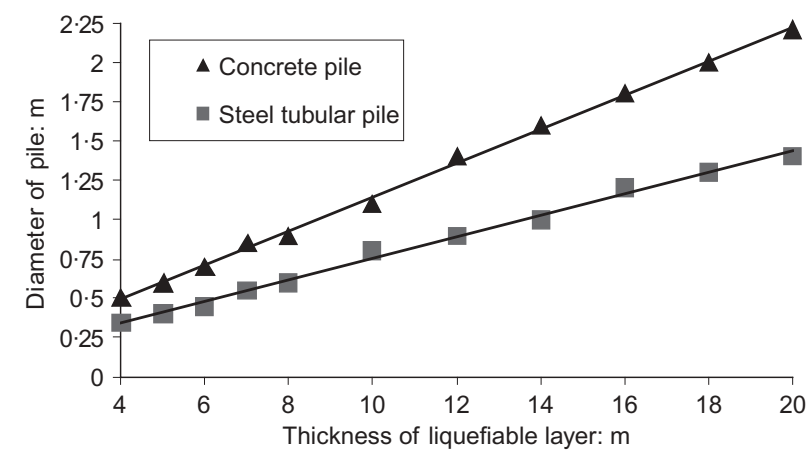

Fig. 21. Design chart for deciding minimum pile diameter based on Euler's buckling theory when $\mathbf{L}_{\text {eff }} / \mathbf{r}_{\min }=\mathbf{5 0}$ (after Bhattacharya and Tokimatsu, 2004) liquefiable and non-liquefiable soil strata. It was also found that embedded pile caps suffered more damage than caps without embedment. It is suggested that, owing to 'lateral spreading' of the liquefied soil, the embedded pile cap is subjected to excessive horizontal thrust. This happens after the soil is completely liquefied, and deformation may possibly continue for a few minutes to a few days. Lateral deformations are observed in waterfront and nearby structures during earthquakes. Pile-supported structures in such regions are prone to fail, as lateral movements are predominant, if they are not adequately designed to cater for earthquake effects.

However, in flat ground where lateral flow is not possible, some pile foundations failed. The underlying non-liquefiable ground may be sloping in nature (Yasuda et al., 1992), in which case internal lateral flow below the top soil crust might occur along the slope. In this regard the discusser would like to mention that the likelihood of 'bending failure' of the pile due to lateral forces exerted on a pile (say $0.5 \mathrm{~m}$ diameter) is negligibly small. Considering the soil in an ideally viscous liquid state, it is highly unlikely that such a small amount of lateral thrust can ever be able to push the entire building resting on piles installed at, for instance, $4 \mathrm{~m}$ centres. Therefore a study of soil-pile-superstructure interaction in liquefying zones seems to be a new research topic.

After Nigata (1964), Alaska (1964) and subsequent earthquakes a lot of anti-liquefaction measures have been developed and adopted in seismic design manuals. Yet during the Kobe (1995) earthquake hundreds of pile foundations (Tokimatsu et al., 1996, 1997) were severely damaged. Referring to Fig. 11(d), the piles used were $0.4 \mathrm{~m}$ diameter hollow prestressed concrete, as shown in Fig. 22(b). The axial load was $41.2 \mathrm{t}$. These piles were constructed within an engineered fill underlain by $12 \mathrm{~m}$ of non-liquefying soil strata. Borehole No. 1 (Oh-Oka et al., 1996) after the earthquake indicated that a $2.5 \mathrm{~m}$ thick good sand layer $(N>7)$ overlies $4 \mathrm{~m}$ of thick weak sandy silt $(N<5)$. Considering the minimum resistance offered by this sandy silt, as well as that offered by the intervening sand layer below the fill, it is

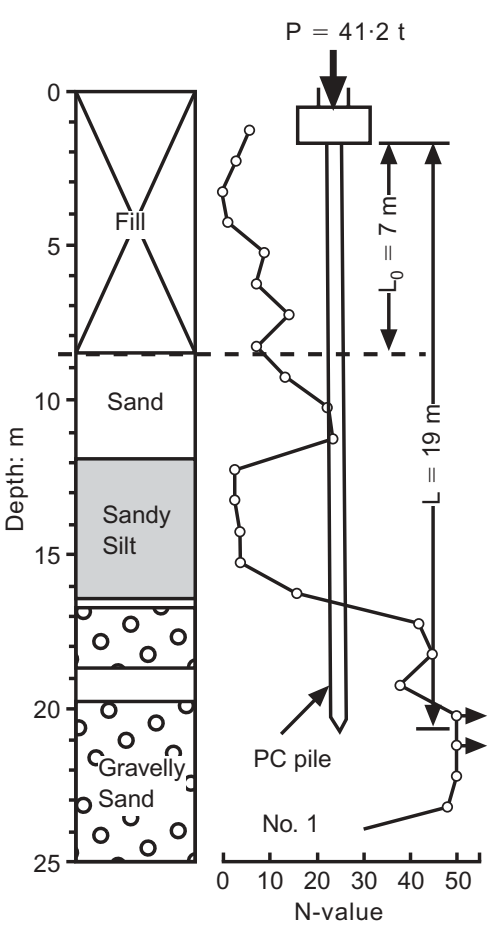

(a)

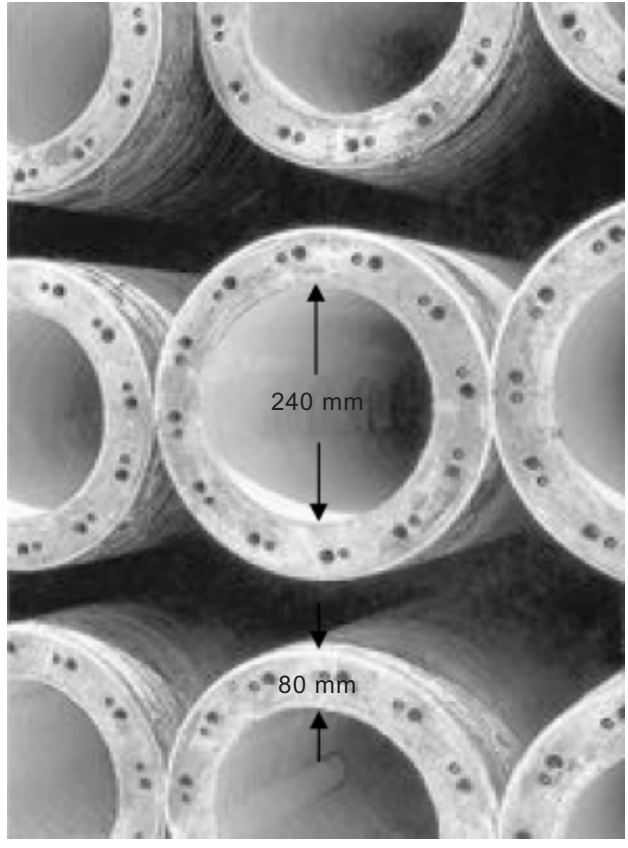

(b)

Fig. 22. Severely damaged piled foundation for three-storey building in Kobe earthquake, 1995 (a) soil profile and (b) precast prestressed concrete (PC type, JISC, 2000) pile used in Fig. 11(d) 
quite possible that the $5 \mathrm{~m}$ of the entire pile, passing into the gravelly sand, was not enough to support the design load. As this building suffered large lateral movement due to proximity to the failed waterfront structure, it may be critically re-examined whether 'lateral spreading' caused pile no. S-7 (Fig. 11(d)) to break, or whether the eccentric weight of the progressively tilted building exceeded the lateral load capacity of the pile.

\section{Authors' reply}

We are grateful for the interest in our work shown by Dr Ghosh. He makes five discussion points, which we address in order.

(a) Each pile needs to be evaluated with respect to its end conditions (fixed, pinned or free). Each pile in a group of identical piles will have the same buckling load as a single pile. If a group of piles is fixed in a stiff pile cap, then the appropriate top boundary condition is one of fixity against rotation; the group may, however, buckle either in side sway or in simple vertical displacement.

(b) The authors began their calculation procedure by declaring the depth $L_{0}$ of a pile into which lateral buckling can take place. This should include the depth of liquefiable soil plus the additional depth for fixity in the non-liquefied layer, if fixity in that layer is assumed. We then modified the length $L_{0}$ using the $\beta$ factor defined at the foot of Table 1 , so as to derive the effective length $L_{\text {eff }}$, accounting for end conditions as explained above.

(c) Perhaps the discusser is referring to the drainage that might allow some compaction of loose sand to occur during an earthquake. The authors have made similar observations in a variety of tests on seismic liquefaction boundary value problems. However, excess pore water pressures signifying full liquefaction (i.e. a state of zero effective stress) have been observed in the free field during model earthquakes in all these cases. The immediate response to total loss of effective stress in the sand surrounding the pile is that all skin friction is lost in that zone, as is all lateral subgrade reaction. It is the elimination of soil effective stress that causes soil stiffness temporarily to disappear, and permits buckling to occur. Of course, the high pore pressures provide a confining pressure around the pile but, following Terzaghi's effective stress principle, the mechanical effect of confining pore pressure is neutral.

(d) The discusser apparently finds it difficult to accept that piles can buckle into soil that liquefies in an earthquake. The authors believe that they have furnished ample proof that this is indeed so. The discusser emphasises that the density of liquefied soil initially equals its previous density. The authors agree, but emphasise their view that the total loss of soil stiffness permits pile buckling to begin, and that hydrostatic pressures are an irrelevant consideration for a buckling strut.

(e) The discusser first rehearses the previous ruling assumption that all lateral pile movements must derive from lateral forces. As we have shown, lateral movements can alternatively be caused by axial forces that cause pile buckling. It is unfortunate that previous researchers on pile bending due to soil liquefaction failed to include axial loads. The reason for putting piles under a building is precisely to transmit axial loads down to a strong stratum. It must now be recognised that axial loads can have a dominant effect on the lateral deformation of slender end-bearing piles. The discusser then seems to agree that $P-\Delta$ effects in piles should henceforward be incorporated into design calculations. Even where buckling does not occur, the influence of axial loads may significantly reduce lateral pile stiffness. If, for example, there were a factor of safety of 3 against sway buckling, elementary structural theory shows that the effective lateral stiffness of the pile reduces by $50 \%$. Geotechnical engineers must not forget their basic structural mechanics.

\section{REFERENCES}

Bhattacharya, S. \& Tokimatsu, K. (2004). Essential criteria for design of piled foundations in seismically liquefiable areas. Proc. 39th Jap. Nat. Conf. Geotech. Engng, Nigata, paper 904, $1805-1806$.

BTL Committee (2000). Study on liquefaction and lateral spreading in the 1995 Hyogoken-Nambu earthquake, Building Research Report No. 138. Building Research Institute, Ministry of Construction, Japan (in Japanese).

Editorial Committee for the Report on the Hanshin-Awaji Earthquake Disaster (1998). Report on the Hanshin-Awaji earthquake disaster, Building Series Vol. 4. Maruzen (in Japanese).

Fujii, S., Isemoto, N., Satou, Y. \& Kaneko, O. (1998). Investigation and analysis of a pile foundation damaged by liquefaction during the 1995 Hyogoken-Nambu earthquake. Soils Found., Special Issue on Geotechnical Aspects of the 17 January 1995 Hyogoken-Nambu Earthquake, No. 2, 179-192.

Hamada, M. \& O'Rourke, T. D. (eds) (1992). Case studies of liquefaction and lifeline performance during past earthquakes, Vol. 1 Japanese case studies, Technical Report NCEER-92-0001. National Centre for Earthquake Engineering Research.

Hanshin Expressway Public Corporation (1997). Geotechnical report of Hanshin Expressway, Route 3 Kobe line and Route 5 Bay line: Restoration from earthquake damage. Hanshin Expressway Public Corporation.

JISC (2000). Precast prestressed concrete products, JIS-A:5373 Pt. 5. Tokyo: Japanese Industrial Standards Committee (in Japanese).

Kawamura, S., Nishizawa, T. \& Wada, H. (1985). Damage to piles due to liquefaction found by excavation twenty years after earthquake. Nikkei Architecture, 27 May, 130-134.

Kinki Branch of Architectural Institute of Japan (1996). Report of damage to foundation of buildings during Hyogoken-nambu earthquake. Kinki Branch of Architectural Institute of Japan (in Japanese)

Oh-Oka, H., Iba, M., Abe, A. \& Tokimatsu, K. (1996). Investigation of earthquake induced damage to pile foundation using televiewer observation and integrity sonic tests. Tsuchi-to-kiso, JGS 44, No. 3, 28-30 (in Japanese).

Shimura, S., Shimada, M., Hiroshige, T., Sato, M. \& Azuma, H. (2000). Behavior of piles nearby caisson type quay wall during earthquakes. Proc. 55th Ann. Conf. Japan Soc. Civ. Engng 1(B), $872-875$ (in Japanese).

Tokimatsu, K., Oh-Oka, H., Shamoto, Y. and Asaka, Y. (1997). Failure and deformation modes of piles due to liquefactioninduced lateral spreading in 1995 Hyogoken-nambu earthquake. J. Structural and Constructional Engng, AIJ, No. 495, 95-100.

Yasuda, S., Nagase, H., Kiku, H. \& Uchida, Y. (1992). The mechanism and simplified procedure for the analysis of permanent ground displacement due to liquefaction. Soils Found. 32, No. $1,149-160$

Yoshida, N. \& Hamada, M. (1990). Damage to foundation piles and deformation pattern of ground due to liquefaction-induced permanent ground deformations. Proc. 3rd Japan-US Workshop on Earthquake Resistant Design of Lifeline Facilities and Countermeasures for Soil Liquefaction, San Francisco, pp. 147-161. 